\title{
Epithelial-mesenchymal transition, cancer stem cells and treatment resistance
}

\author{
Bhuvanesh Dave', Vivek Mittal ${ }^{2}$, Nicholas M Tan' and Jenny C Chang ${ }^{1 *}$
}

\begin{abstract}
Breast cancer relapse, in a large number of patients, after initial response to standard of care therapy warrants development of novel therapies against recurrent and metastatic cancer. Cancer stem cells (CSCs), present in breast tumors while being intrinsically resistant to conventional therapy, have the ability to self renew and cause tumor recurrence. The residual tumors after therapy, with dramatic enrichment of the CSCs, have all the hallmarks of epithelial- mesenchymal transition (EMT). This review will focus on the link between EMT, CSCs and treatment resistance, since a better understanding of these interactions will allow us to effectively target the residual population after therapy.
\end{abstract}

\section{Introduction}

Mortality from breast cancer has steadily been declining over the past decade, primarily due to earlier detection, adjuvant therapies and the advent of targeted therapies for estrogen receptor-positive and HER2-positive cancers $[1,2]$. Despite these advances, a large number of patients relapse after an initial response to standard-of-care therapy. Novel therapies that prevent breast cancer relapse and metastasis are needed.

An emerging hypothesis is that tumors contain a subpopulation of cells, called cancer stem cells (CSCs), which have the ability to self-renew and regenerate the tumor. Increasingly, clinical evidence points to an intrinsic resistance to endocrine therapy and chemotherapy of this subpopulation of CSCs [3]. The residual tumors after chemotherapy are enriched for CSCs and have a gene signature with hallmarks of epithelialmesenchymal transition (EMT)-like properties [3,4]. The

*Correspondence: jcchang@tmhs.org

'Methodist Hospital Cancer Center, 6550 Fannin Street SM383, Houston, TX 77030, USA

Full list of author information is available at the end of the article present review is a step in developing an understanding of the nature of treatment resistance and the role that EMT and CSCs play in this process.

\section{Epithelial-mesenchymal transition pathway}

EMT is a process by which the epithelial cells change to a mesenchymal phenotype. This process involves an increase in fibroid morphology, invasiveness, resistance to apoptosis and an increase in extracellular matrix components [5,6]. The acquisition of EMT in the epithelium of an organ may be one of the initial steps on the path to tumorigenesis [7]. EMT has more recently been linked to the progression of cancer and increased stemness of tumors [8]. This correlation between EMT and CSCs may provide a direct link between the CSCs and the metastatic potential of cancer. An increase in EMT markers has thus been linked with aggressiveness of metastatic disease, which may be explained by increasing stemness of tumor-initiating CSCs and intrinsic resistance to standard therapies.

EMT can be induced by signals from the stroma associated with tumors - such as hepatocyte growth factor, platelet-derived growth factor, and transforming growth factor beta - together with a series of EMTinducing transcription factors such as Snail, Slug, zinc finger E-box binding homeobox 1 (ZEB1), ZEB2, Twist, Goosecoid, and FOXC2 [7,9,10]. A negative feedback pathway involving ZEB1, ZEB2 and transforming growth factor beta may be responsible for regulating EMT. The transforming growth factor beta/SMAD1/LEF/plateletderived growth factor axis is also described as being important for EMT signaling [7]. Along with these transcription factors, the miRNAs play a role in EMT; specifically, downregulation of the miR-200 family causes an induction of EMT. The details of the interaction of all these factors with each other are currently under investigation (Figure 1).

\section{Breast cancer stem cells}

Breast cancer can be classified as a series of diseases based on its different subtypes. Traditionally, immunohistochemistry has been used to describe the different subtypes of cancer. Recent use of microarray analysis, 


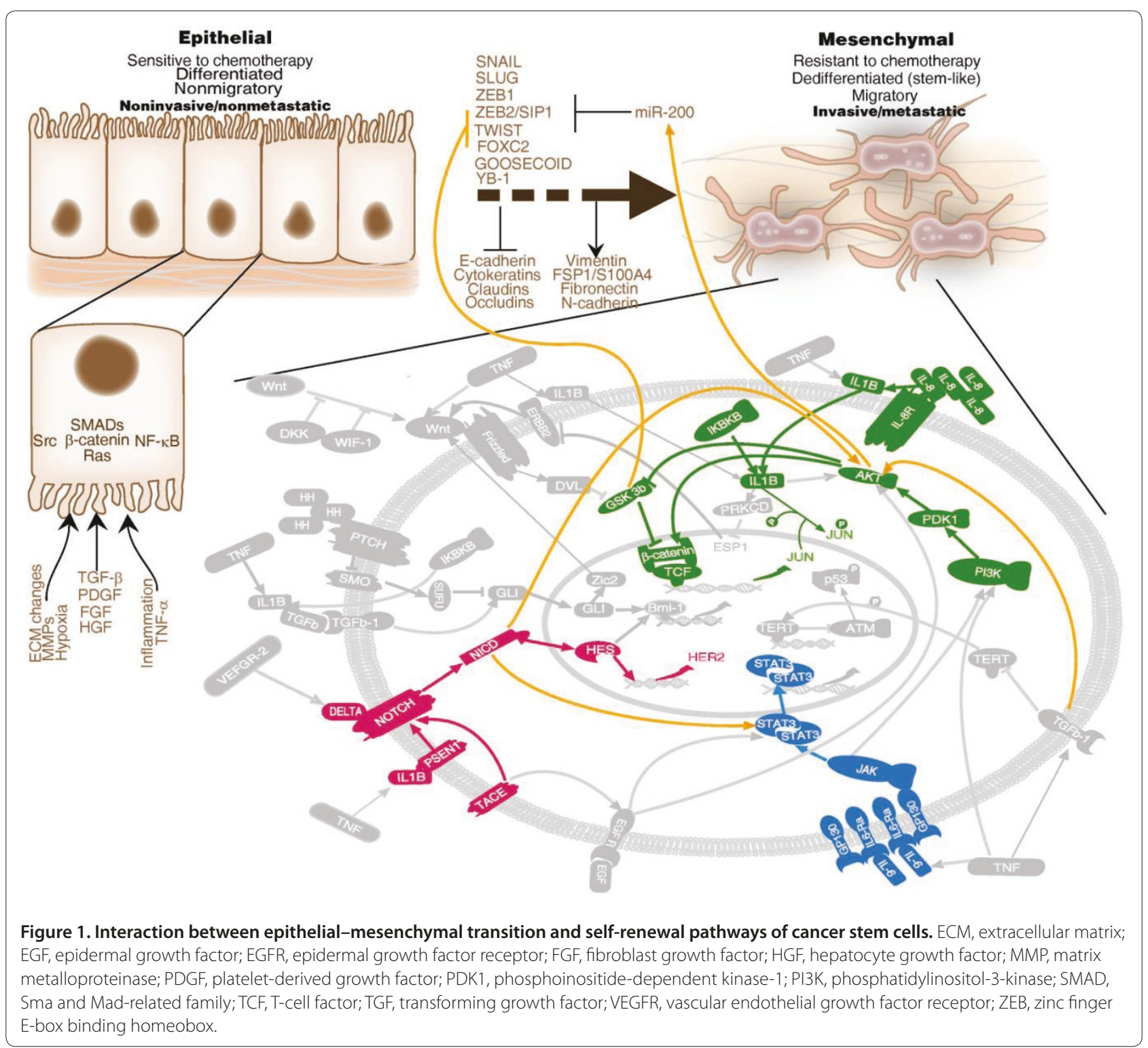

however, has provided a more coherent tool to separate these subtypes into luminal A, luminal B, HER2-positive, basal, normal-like and a new subtype called claudin-lowlike, which displays spindeloid features and EMT-like properties [11].

The breast CSCs were initially identified based on a seminal paper from Dr Michael Clarke and Dr Max Wicha's group that identified them as being enriched for CD $44^{+} / \mathrm{CD} 24^{-/ \text {low }}$ cells and having the ability to form tumors at a much higher frequency than the bulk tumor [12]. More recently, ALDH1 levels as identified by the ALDefluor assay were also demonstrated to enrich the CSCs $[13,14]$. Apart from flow cytometry analysis of stem cell markers, the ability of tumor cells to form mammospheres (spheres of cells formed under ultra-low attachment conditions, in serum-free media supplemented with growth factors) as a surrogate assay of the stemness of the cells has been described [13,14]. This ability is calculated as a percentage and called the mammosphere-forming efficiency (MFSE). The MFSE as a reflection of stemness is generally confirmed with limiting dilution transplantation assays where the tumors enriched for CSC markers form xenograft outgrowths with 10 to 200 cells - compared with 100,000 or more of the other tumor cells, which fail to form tumors. These supporting data point to a population of cells that is responsible for tumor initiation and self-renewal. However, there is a caveat to this hypothesis. There is currently no evidence that any cell within the tumor cannot become stem-like on exposure to various 
treatments, thus alluding to the possibility of plasticity of cells, allowing for transition from one cell type to another.

\section{Treatment resistance}

CSCs may have an intrinsic resistance to therapy [4]. Current treatment strategies may therefore affect the bulk of the tumor cells but leave CSCs behind, serving as a starting point for disease recurrence. Similar to the ability of the dandelion roots to regenerate weeds, tumor regrowth from an intrinsically therapy-resistant subpopulation has been termed the dandelion hypothesis [15]. If this hypothesis is true, then understanding the mechanisms responsible for this intrinsic resistance will lead to development of new therapies that will target the CSCs in conjunction with current standard-of-care therapies that could critically impact the overall patient survival.

Clinically, the evidence for breast CSCs is supported by a study in which paired tumor core biopsies taken from patients with breast cancer prior to and during the 12-week treatment with chemotherapy demonstrated an increase in CSC markers (CD44+/CD24-/low and MFSE) with treatment [3]. Conversely, patients with HER2positive disease who received neoadjuvant lapatinib (epidermal growth factor receptor/HER2 inhibitor) for 6 weeks demonstrated a reduction in the percentage of CSCs as evidenced by a decrease in the MFSE and CD44+/CD24-/low levels in residual tumors [4]. This suggests that the CSCs may be resistant to chemotherapy but may be targeted by therapy directed against the HER2 proto-oncogene.

Further investigation into these tumor biopsies to identify the processes involved in CSCs led to the identification of a gene signature for breast CSCs [8]. Briefly, RNA was isolated from these $\mathrm{CD} 44^{+} / \mathrm{CD} 24^{- \text {llow }}$-positive cells as well as mammospheres formed from these patient samples, and microarray analysis was performed. This involved comparing the gene expression of CD44 $4^{+} \mathrm{CD} 24^{-}$ llow versus bulk tumor and of mammosphere-forming cells versus bulk tumor [4]. Genes that increased or decreased in both datasets of CSC markers were combined to give us a gene signature for CSCs, which matched the claudinlow-like phenotype. Claudin-low-like tumors were recently identified and represent only about $5 \%$ of all breast tumors. One of the most important properties of these tumors is that they display EMT-like characteristics, and have high expression of vimentin and Twist.

In addition to claudin-low-like tumors, another rare subtype of breast cancer (metaplastic tumors) was recently found to share molecular similarities with CSCs. These metaplastic tumors are highly chemoresistant and aggressive tumors, characterized by squamous metaplasia of malignant breast epithelium [16]. Hennessey and colleagues demonstrated recently that a set of 28 metaplastic tumors had CSC-like characteristics based on transcriptional profiling using our published CSC signature [17]. These tumors also showed EMT-like characteristics, along with increased mutations and amplification/activation of the phosphatidylinositol-3kinase/AKT pathway. More recently, it has been shown that both metaplastic and the claudin-low-like tumor interactome have EMT-like properties [18]. These results from claudin-low-like and metaplastic tumors suggest a hierarchical nature of breast cancer where tumors arise from changes occurring early in a hierarchy, rather than late, which are observed in the more differentiated tumors.

\section{Epithelial-mesenchymal transition in cancer stem cells}

EMT proceeds in a series of steps, where cells eventually acquire a more spindle-shaped morphology. This involves gradual loss of cell-cell adhesions, tight junctions that facilitate cell-cell interactions, which eventually leads to the reorganization of the cytoskeleton, with loss of apical polarity, and finally the epithelium conversion to spindeloid morphology [16,19-23]. In EMT, the cancer cells acquire the ability to invade into the surrounding microenvironment and thus may lead to relapse and metastases.

Using an in vitro method, Mani and colleagues reported the induction of EMT in immortalized human mammary epithelial cells (HMLERs), by ectopic expression of either the Twist or Snail transcription factors. The overexpression of Twist or Snail made the HMLERs more mesenchymal in nature, with an increased ability to form mammospheres and an increased expression of $\mathrm{CD} 44^{+} /$ CD24-/low CSC markers [24]. These data support a direct link between EMT and loss of epithelial properties and gain of CSC-like properties. Further work by the same group has shown that $F O X C 2$ may play a key role in the induction of EMT in vitro and this is corroborated by the tumorigenic signature from our group, thus suggesting that $F O X C 2$ may play a role in development of EMT and in CSCs self-renewal [25].

EMT was rarely found in bulk primary tumors as shown by loss of heterozygosity studies, which compare the epithelial and stromal compartments of breast cancers [23]. EMT has been described to play a role in the invasion-metastases cascade in some invasive cancers, however, suggesting that EMT may be working in the CSC milieu. In both normal cells and breast CSCs a low expression of the miR-200 family of miRNAs has been shown to increase EMT [26], probably via their known negative regulation of Zeb1 and Zeb2. Both normal cells and breast CSCs have also been shown to express low levels of the miR-200 family of miRNAs, which are known to negatively regulate transcription 
factors Zeb1 and Zeb2 and to promote EMT. METs is an important component of tumor metastasis since once the tumor moves from its primary site to a secondary site it has to undergo mesenchymal-epithelial transformation (MET) in order to generate a tumor similar to the one at the primary site of breast cancer.

\section{Mesenchymal-epithelial transition in tumorigenesis}

EMT endows metastatic properties upon cancer cells to promote invasion, migration, and subsequent dissemination [27]. Following dissemination, establishment of metastatic lesions depends on the organ-colonizing properties of disseminated tumor cells as well as on permissive conditions also referred to as the metastatic niche that may be present in the restrictive microenvironment of target organs [28,29]. For instance, recruited bone-marrow-derived vascular endothelial growth factor receptor-1-positive cells were able to generate a premetastatic niche in the lungs to support initiation of metastases in one study [30], while another study demonstrated the role of bone-marrow-derived c-kitpositive VE-cadherin-positive endothelial progenitor cells in angiogenesis-mediated progression of micrometastases to macrometastases [31].

The observation that the cancer cells in metastatic lesions exhibit an epithelial phenotype that resembles the primary tumor from which they were derived has led to speculation that the disseminated tumor cells recruited into the target organs may undergo MET that would favor metastasis formation [32,33]. The MET cascade has not been recapitulated in tumor progression, however, and the cellular and molecular regulators that promote MET of metastatic tumor cells remain unknown. Notably, MET is an essential developmental process and has been extensively studied in kidney organogenesis and somitogenesis [34]. Importantly, during kidney development, the conversion of metanephric mesenchyme to epithelium [35] involves MET that is regulated by versican. Indeed, ectopic expression of versican in NIH3T3 fibroblasts in culture resulted in an epithelial phenotype [36]. Given that versican expression is confined to the stroma [37-42], there is a possibility that the disseminated cancer cells may undergo MET under the influence of local microenvironments that they encounter in the parenchyma of the distant organ. Another possibility is that this microenvironment may also lack the heterotypic signals that promote EMT [7].

\section{Conclusions}

CSCs display EMT characteristics, which are a critical component of treatment resistance in breast tumors. Our studies on the tumorigenic signature have identified increases in VIM and MMP-2 along with FOXC2 in letrozole/chemotherapy-treated specimens, and immunohistochemistry studies have indicated an increase in epithelial cells undergoing EMT in post-treatment biopsies. These observations have been discussed in greater detail elsewhere [43]. Other studies have shown that the onset of EMT leads to an increase in the subpopulation of CSCs as described by an increase in various markers involved in the pathway. Overall, the literature supports EMT playing a major role in sustaining the CSCs, which leads to an increase in the metastatic potential of breast cancer. A better understanding of the role of EMT and CSCs in breast cancer will lead to more effective therapies that will target not only the bulk tumor but also the residual population of cells that are responsible for the relapse and resurgence of the tumor. It is imperative to study EMT and CSCs together in order to have a better understanding of treatment resistance in breast cancer. Further examination of the epigenetic changes such as miRNA will also be an important area of research.

This article is part of a review series on EMT and the connection with stem cells, edited by Dr Jenny Chang.

\section{Abbreviations}

CSC, cancer stem cell; EMT, epithelial-mesenchymal transition; HMLER, human mammary epithelial cell overexpressing hTERT, SV40 T/t and H-RasV12; MET, mesenchymal-epithelial transition; MFSE, mammosphere-forming efficiency; miRNA, microRNA; ZEB, zinc finger E-box binding homeobox.

\section{Competing interests}

The authors declare that they have no competing interests.

\section{Acknowledgements}

The authors would like to thank Dr Stephen T Wong for his illustrations and his input.

\section{Author details}

'Methodist Hospital Cancer Center, 6550 Fannin Street SM383, Houston, TX 77030, USA. ${ }^{2}$ Weil Cornell Medical School.

Published: 19 January 2012

\section{References}

1. Berry DA, Cronin KA, Plevritis SK, Fryback DG, Clarke L, Zelen M, Mandelblatt JS, Yakovlev AY, Habbema JD, Feuer EJ: Effect of screening and adjuvant therapy on mortality from breast cancer. N Engl J Med 2005, 353:1784-1792.

2. Fong P: Mouse models for human epithelial disease: novel insights and new horizons. Exp Physio/ 2009, 94:169-170.

3. Chang JC, Wooten EC, Tsimelzon A, Hilsenbeck SG, Gutierrez MC, Tham YL, Kalidas M, Elledge R, Mohsin S, Osborne CK, Chamness GC, Allred DC, Lewis MT, Wong $\mathrm{H}, \mathrm{O}^{\prime} \mathrm{C}$. to docetaxel by gene expression profiling in breast cancer patients. J Clin Oncol 2005, 23:1169-1177.

4. Li X, Lewis MT, Huang J, Gutierrez C, Osborne CK, Wu MF, Hilsenbeck SG, Pavlick A, Zhang X, Chamness GC, Wong H, Rosen J, Chang JC: Intrinsic resistance of tumorigenic breast cancer cells to chemotherapy. J Natl Cancer Inst 2008, 100:672-679.

5. Kalluri R, Neilson EG: Epithelial-mesenchymal transition and its implications for fibrosis. J Clin Invest 2003, 112:1776-1784.

6. Hay ED: An overview of epithelio-mesenchymal transformation. Acta Anat (Basel) 1995, 154:8-20.

7. Thiery JP: Epithelial-mesenchymal transitions in tumour progression. Nat 
Rev Cancer 2002, 2:442-454

8. Creighton CJ, Li X, Landis M, Dixon JM, Neumeister VM, Sjolund A, Rimm DL, Wong H, Rodriguez A, Herschkowitz JI Fan C, Zhang X, He X, Pavlick A, Gutierrez MC, Renshaw L, Larionov AA, Faratian D, Hilsenbeck SG, Perou CM, Lewis MT, Rosen JM, Chang JC: Residual breast cancers after conventional therapy display mesenchymal as well as tumor-initiating features. Proc Natl Acad Sci U S A 2009, 106:13820-13825.

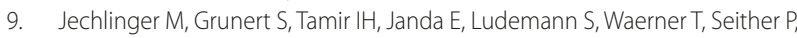
Weith $\mathrm{A}$, Beug $\mathrm{H}$, Kraut N: Expression profiling of epithelial plasticity in tumor progression. Oncogene 2003, 22:7155-7169.

10. Shi Y, Massague J: Mechanisms of TGF- $\beta$ signaling from cell membrane to the nucleus. Cell 2003, 113:685-700.

11. Herschkowitz JI, Simin K, Weigman VJ, Mikaelian I, Usary J, Hu Z, Rasmussen KE, Jones LP, Assefnia S, Chandrasekharan S Backlund MG, Yin Y, Khramtsov Al, Bastein R, Quackenbush J, Glazer RI, Brown PH, Green JE, Kopelovich L, Furth PA, Palazzo JP, Olopade OI, Bernard PS, Churchill GA, Van Dyke T, Perou CM: Identification of conserved gene expression features between murine mammary carcinoma models and human breast tumors. Genome Bio/ 2007, 8:R76.

12. Al-Hajj M, Wicha MS, Benito-Hernandez A, Morrison SJ, Clarke MF: Prospective identification of tumorigenic breast cancer cells. Proc Natl Acad Sci U S A 2003, 100:3983-3988.

13. Dontu G, Wicha MS: Survival of mammary stem cells in suspension culture: implications for stem cell biology and neoplasia. J Mammary Gland Biol Neoplasia 2005, 10:75-86

14. Ginestier C, Hur MH, Charafe-Jauffret E, Monville F, Dutcher J, Brown M, Jacquemier J, Viens P, Kleer CG, Liu S Schott A, Hayes D, Birnbaum D, Wicha MS, Dontu G: ALDH1 is a marker of normal and malignant human mammary stem cells and a predictor of poor clinical outcome. Cell Stem Cell 2007, 1:555-567.

15. Jones RJ, Matsui WH, Smith BD: Cancer stem cells: are we missing the target? J Nat/ Cancer Inst 2004, 96:583-585.

16. Lee JM, Dedhar S, Kalluri R, Thompson EW: The epithelial-mesenchymal transition: new insights in signaling, development, and disease. J Cell Biol 2006, 172:973-981

17. Hennessy BT, Gonzalez-Angulo AM, Stemke-Hale K, Gilcrease MZ, Krishnamurthy S, Lee JS, Fridlyand J, Sahin A, Agarwal R, Joy C Liu W, Stivers D, Baggerly K, Carey M, Lluch A, Monteagudo C, He X, Weigman V, Fan C, Palazzo J, Hortobagyi GN, Nolden LK, Wang NJ, Valero V, Gray JW, Perou CM, Mills GB: Characterization of a naturally occurring breast cancer subset enriched in epithelial-to-mesenchymal transition and stem cell characteristics. Cancer Res 2009, 69:4116-4124.

18. Taube JH, Herschkowitz Jl, Komurov K, Zhou AY, Gupta S, Yang J, Hartwell K, Onder TT, Gupta PB, Evans KW, Hollier BG, Ram PT, Lander ES, Rosen JM, Weinberg RA, Mani SA: Core epithelial-to-mesenchymal transition interactome gene-expression signature is associated with claudin-low and metaplastic breast cancer subtypes. Proc Natl Acad Sci U S A 2010 107:15449-15454

19. Guarino M, Rubino B, Ballabio G: The role of epithelial-mesenchymal transition in cancer pathology. Pathology 2007, 39:305-318.

20. Damonte P, Gregg JP, Borowsky AD, Keister BA, Cardiff RD: EMT tumorigenesis in the mouse mammary gland. Lab Invest 2007, 87:1218-1226

21. Kokkinos MI, Wafai R, Wong MK, Newgreen DF, Thompson EW, Waltham M: Vimentin and epithelial-mesenchymal transition in human breast cancer - observations in vitro and in vivo. Cells Tissues Organs 2007, 185:191-203.

22. Sarrio D, Rodriguez-Pinilla SM, Hardisson D, Cano A, Moreno-Bueno G, Palacios J: Epithelial-mesenchymal transition in breast cancer relates to the basal-like phenotype. Cancer Res 2008, 68:989-997.

23. Trimboli AJ, Fukino K, de Bruin A, Wei G, Shen L, Tanner SM, Creasap N, Rosol TJ, Robinson ML, Eng C, Ostrowski MC, Leone G: Direct evidence for epithelial-mesenchymal transitions in breast cancer. Cancer Res 2008 68:937-945

24. Mani SA, Guo W, Liao MJ, Eaton EN, Ayyanan A, Zhou AY, Brooks M, Reinhard F, Zhang CC, Shipitsin M Campbell LL, Polyak K, Brisken C, Yang J, Weinberg RA: The epithelial-mesenchymal transition generates cells with properties of stem cells. Cell 2008, 133:704-715.

25. Mani SA, Yang J, Brooks M, Schwaninger G, Zhou A, Miura N, Kutok JL, Hartwell K, Richardson AL, Weinberg RA: Mesenchyme Forkhead 1 (FOXC2) plays a key role in metastasis and is associated with aggressive basal-like breast cancers. Proc Natl Acad Sci U S A 2007, 104:10069-10074.

26. Shimono Y, Zabala M, Cho RW, Lobo N, Dalerba P, Qian D, Diehn M, Liu H, Panula SP, Chiao E, Dirbas FM, Somlo G, Pera RA, Lao K, Clarke MF: Downregulation of miRNA-200c links breast cancer stem cells with normal stem cells. Cell 2009, 138:592-603.

27. Polyak K, Weinberg RA: Transitions between epithelial and mesenchymal states: acquisition of malignant and stem cell traits. Nat Rev Cancer 2009, 9:265-273

28. Gupta GP, Massague J: Cancer metastasis: building a framework. Cell 2006, 127:679-695

29. Fidler IJ: The pathogenesis of cancer metastasis: the 'seed and soil' hypothesis revisited. Nat Rev Cancer 2003, 3:453-458.

30. Kaplan RN, Riba RD, Zacharoulis S, Bramley AH, Vincent L, Costa C, MacDonald DD, Jin DK, Shido K, Kerns SA Zhu Z, Hicklin D, Wu Y, Port JL, Altorki N, Port ER, Ruggero D, Shmelkov SV, Jensen KK, Rafii S, Lyden D: VEGFR1-positive haematopoietic bone marrow progenitors initiate the pre-metastatic niche. Nature 2005, 438:820-827.

31. Gao D, Nolan DJ, Mellick AS, Bambino K, McDonnell K, Mittal V: Endothelial progenitor cells control the angiogenic switch in mouse lung metastasis. Science 2008, 319:195-198.

32. Hugo $H$, Ackland ML, Blick T, Lawrence MG, Clements JA, Williams ED, Thompson EW: Epithelial-mesenchymal and mesenchymal-epithelial transitions in carcinoma progression. J Cell Physiol 2007, 213:374-383.

33. Chaffer CL, Thompson EW, Williams ED: Mesenchymal to epithelial transition in development and disease. Cells Tissues Organs 2007, 185:7-19.

34. Zeisberg M, Shah AA, Kalluri R: Bone morphogenic protein-7 induces mesenchymal to epithelial transition in adult renal fibroblasts and facilitates regeneration of injured kidney. J Bio/ Chem 2005, 280:8094-8100.

35. Vainio S, Lin Y: Coordinating early kidney development: lessons from gene targeting. Nat Rev Genet 2002, 3:533-543.

36. Sheng W, Wang G, La Pierre DP, Wen J, Deng Z, Wong CK, Lee DY, Yang BB: Versican mediates mesenchymal-epithelial transition. Mol Biol Cell 2006, 17:2009-2020

37. Suwiwat S, Ricciardelli C, Tammi R, Tammi M, Auvinen P, Kosma VM, LeBaron $R G$, Raymond WA, Tilley WD, Horsfall DJ: Expression of extracellular matrix components versican, chondroitin sulfate, tenascin, and hyaluronan, and their association with disease outcome in node-negative breast cancer. Clin Cancer Res 2004, 10:2491-2498.

38. Ricciardelli C, Brooks JH, Suwiwat S, Sakko AJ, Mayne K, Raymond WA Seshadri R, LeBaron RG, Horsfall DJ: Regulation of stromal versican expression by breast cancer cells and importance to relapse-free survival in patients with node-negative primary breast cancer. Clin Cancer Res 2002, 8:1054-1060.

39. Pukkila M, Kosunen A, Ropponen K, Virtaniemi J, Kellokoski J, Kumpulainen E Pirinen R, Nuutinen J, Johansson R, Kosma VM: High stromal versican expression predicts unfavourable outcome in oral squamous cell carcinoma. J Clin Pathol 2007, 60:267-272.

40. Kodama J, Hasengaowa, Kusumoto T, Seki N, Matsuo T, Ojima Y, Nakamura K, Hongo A, Hiramatsu Y: Prognostic significance of stromal versican expression in human endometrial cancer. Ann Oncol 2007, 18:269-274.

41. Pirinen R, Leinonen T, Bohm J, Johansson R, Ropponen K, Kumpulainen E, Kosma VM: Versican in nonsmall cell lung cancer: relation to hyaluronan, clinicopathologic factors, and prognosis. Hum Pathol 2005, 36:44-50.

42. Pukkila MJ, Kosunen AS, Virtaniemi JA, Kumpulainen EJ, Johansson RT, Kellokoski JK, Nuutinen J, Kosma VM: Versican expression in pharyngeal squamous cell carcinoma: an immunohistochemical study. J Clin Pathol 2004, 57:735-739.

43. Creighton CJ, Chang JC, Rosen JM: Epithelial-mesenchymal transition (EMT) in tumor-initiating cells and its clinical implications in breast cancer. J Mammary Gland Biol Neoplasia 2010, 15:253-260.

doi:10.1186/bcr2938

Cite this article as: Dave B, et al:: Epithelial-mesenchymal transition, cancer stem cells and treatment resistance. Breast Cancer Research 2012, 14:202. 